\title{
A unique bleeding-related complication of sorafenib, a tyrosine kinase inhibitor, in advanced hepatocellular carcinoma: a case report
}

Ha Yan Kang ${ }^{1}$, Sung Hoon Moon ${ }^{2}$ and II Han Song ${ }^{1 *}$

\begin{abstract}
Introduction: Sorafenib, a multikinase inhibitor as a standard of care for advanced hepatocellular carcinoma, may lead endothelial cells to an unstable state by blocking the signaling pathway of vascular endothelial growth factor receptor, which may result in the disruption of the architecture and integrity of the microvasculature, and eventually increase the risk of hemorrhage. Hemobilia is a relatively uncommon condition as a consequence of hepatocellular carcinoma and its risk factors remain uncertain.
\end{abstract}

Case presentation: Here we report a unique case of hemobilia occurring in a 55-year-old Korean man with hepatitis B virus-related hepatocellular carcinoma on Barcelona Clinic Liver Cancer advanced stage after seven days of treatment with sorafenib. He had received prior radiation therapy. Endoscopy revealed bleeding from the major duodenal papilla and endoscopic retrograde cholangiography revealed an amorphous filling defect throughout the common bile duct. Blood clots were removed by balloon sweeping and a nasobiliary drainage tube was placed. No further bleeding has been detected as of eight months after discontinuation of sorafenib.

Conclusion: Sorafenib may increase the risk of biliary bleeding in hepatocellular carcinoma patients who were primed with irradiation, by blocking the signaling pathway of the vascular endothelial growth factor receptor. Therefore, sorafenib should be used with caution in patients with advanced hepatocellular carcinoma, especially when combined with radiation therapy.

Keywords: Hepatocellular carcinoma, Sorafenib, Tyrosine kinase inhibitor, Hemobilia, Complication

\section{Introduction}

Hemobilia is a very rare manifestation of hepatocellular carcinoma (HCC) [1]. Almost all cases occur in patients who have accompanying bile duct invasion [2,3]; however, the predisposing factors in these patients are uncertain. Sorafenib, a multikinase inhibitor, is recognized as a standard of care for advanced HCC accompanied by extrahepatic spreading or macrovascular invasion. Recently, it was thought that sorafenib can increase the risk of hemorrhage by inhibiting a signaling pathway of the vascular endothelial growth factor (VEGF) receptor [4]. Bleeding events, which can be caused by anti-VEGF signaling therapy, such as sorafenib, sunitinib or bevacizumab, include epistaxis,

\footnotetext{
* Correspondence: ihsong21@dankook.ac.kr

'Division of Hepatology, Department of Internal Medicine, Dankook University College of Medicine, 16-5 Anseo-dong, Cheonan 330-715, Chungnam, Republic of Korea

Full list of author information is available at the end of the article
}

hemoptysis, gastrointestinal bleeding, vaginal bleeding and brain hemorrhage [5]. Epistaxis is the most commonly reported bleeding episode which is self-limited to dose adjustment; however, gastrointestinal bleedings inclusive of pulmonary or intracranial hemorrhage are reported relatively less often but may be fatal $[4,6]$. Here, we report a case of hemobilia occurring in a patient with advanced $\mathrm{HCC}$ after administration of sorafenib, with a review of the literature.

\section{Case presentation}

A 55-year-old Korean man with $\mathrm{HCC}$ associated with liver cirrhosis secondary to chronic hepatitis B virus infection was admitted because of hematemesis and epigastric pain. He had undergone five sessions of transhepatic arterial chemoembolization therapy in the past 12 months. Three weeks previously, he had received radiation therapy due to bone metastasis at the level of the 11th thoracic vertebra 
with spinal cord compression and then, one week previously, sorafenib was started at a dose of $400 \mathrm{mg}$ twice daily. At that time, our patient's Child-Pugh's classification was A and Eastern Cooperative Oncology Group performance score was 2.

On admission, his blood pressure was $120 / 80 \mathrm{mmHg}$ and pulse rate was 74 beats per minute. Digital rectal examination was negative and a small amount of fresh blood was drained via a nasogastric tube. Laboratory data included the following: hemoglobin $15.3 \mathrm{~g} / \mathrm{dL}$, platelet $26,000 / \mathrm{mm}^{3}$, total bilirubin $12.2 \mathrm{mg} / \mathrm{dL}$, albumin $4.1 \mathrm{~g} / \mathrm{dL}$, aspartate aminotransferase 192U/L, alanine aminotransferase 181U/L, alkaline phosphatase 301IU/L, gamma glutamyltransferase $137 \mathrm{U} / \mathrm{L}$, amylase $58 \mathrm{U} / \mathrm{L}$, lipase $26 \mathrm{U} / \mathrm{L}$ and a prothrombin time of 16.7 seconds. Child-Pugh's classification was B.

Abdominal computed tomography (CT) demonstrated a thrombus in the posterior branch of right portal vein (Figure 1A) and dilatation of intrahepatic bile duct (Figure 1B) adjacent to a partially lipiodolized nodule in the portal-venous phase. Upper gastrointestinal endoscopy showed fresh blood emerging from major duodenal papilla (Figure 2). Endoscopic retrograde cholangiography revealed an amorphous filling defect throughout the common bile duct (Figure 3A). Blood clots were removed by balloon sweeping (Figure $3 \mathrm{~B}$ ) and a nasobiliary drainage tube was placed.

After discontinuation of sorafenib administration, with a regular irrigation of saline via nasobiliary tube, our patient became hemodynamically stable and total bilirubin level decreased to $4.6 \mathrm{mg} / \mathrm{dL}$. He was discharged and no further bleeding has been detected as of eight months after the episode.

\section{Discussion}

Hemobilia is a relatively uncommon cause of gastrointestinal bleeding and is usually associated with trauma, cholelithiasis, acalculous inflammatory diseases, vascular disorders and tumors. When HCC invades the biliary tree, hemobilia can occur due to rupture of the tumor into the biliary system [2]. In our present case, tumor invasion into the intrahepatic bile duct was suspicious, but not definite on the abdominal imaging scan.

Kojiro et al. [3] found hemobilia occurring in 5 (21\%) of $24 \mathrm{HCC}$ cases with tumor growth within bile ducts; however, it is unclear how many cases of hemobilia develop in patients with $\mathrm{HCC}$ and what the predisposing factors are. Verset et al. [7] has reported two cases of fatal hemobilia in patients with advanced HCC on the second and seventh day after sorafenib therapy and our present patient was also admitted with hematemesis on the seventh day after sorafenib administration. Adverse events of VEGF receptor-targeted agents relevant to bleeding have been usually reported to occur early in the course of treatment $[8,9]$. Sorafenib administration itself may be the potential cause of the development of gastrointestinal bleeding presented as hemobilia in our patient.

Sorafenib is a small molecule inhibitor of multiple tyrosine kinase receptors that regulates cell proliferation and angiogenesis. It is now the standard of care for patients with advanced-stage HCC with macrovascular invasion or extrahepatic spread $[5,10]$. Rash, exfoliative dermatitis, hand-foot skin reaction, diarrhea, fatigue and hypertension are common adverse effects of sorafenib $[4,11]$. Although there are still some debates whether sorafenib may increase the risk of bleeding, a recent metaanalysis showed a significant two-times increased risk of a bleeding event in cancer patients treated with sorafenib or sunitinib [12]. These bleeding events can be thought of as being associated with the aberrant disruption of VEGF signaling involved in mechanisms related to vascularization and coagulation. VEGF stimulates endothelial cell proliferation as well as promotes endothelial cell survival, which, consequently, helps maintain
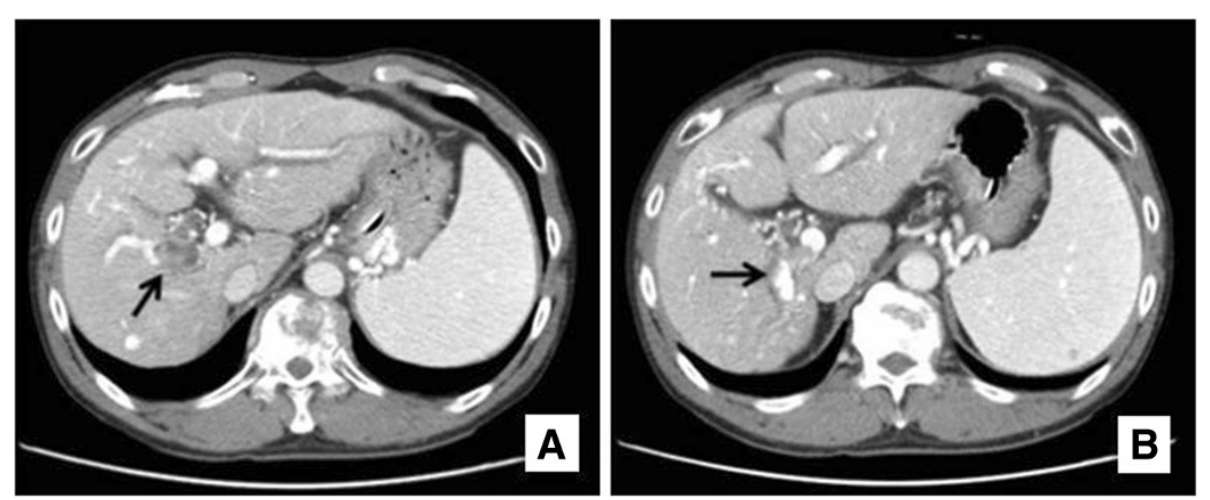

Figure 1 Computed tomography. (A) A thrombus was noted in the posterior branch of right portal vein (arrow). (B) Dilatation of intrahepatic duct (arrow) adjacent to a partially lipiodolized nodule suggested direct invasion of the tumor into the surrounding intrahepatic duct in the portal-venous phase. 


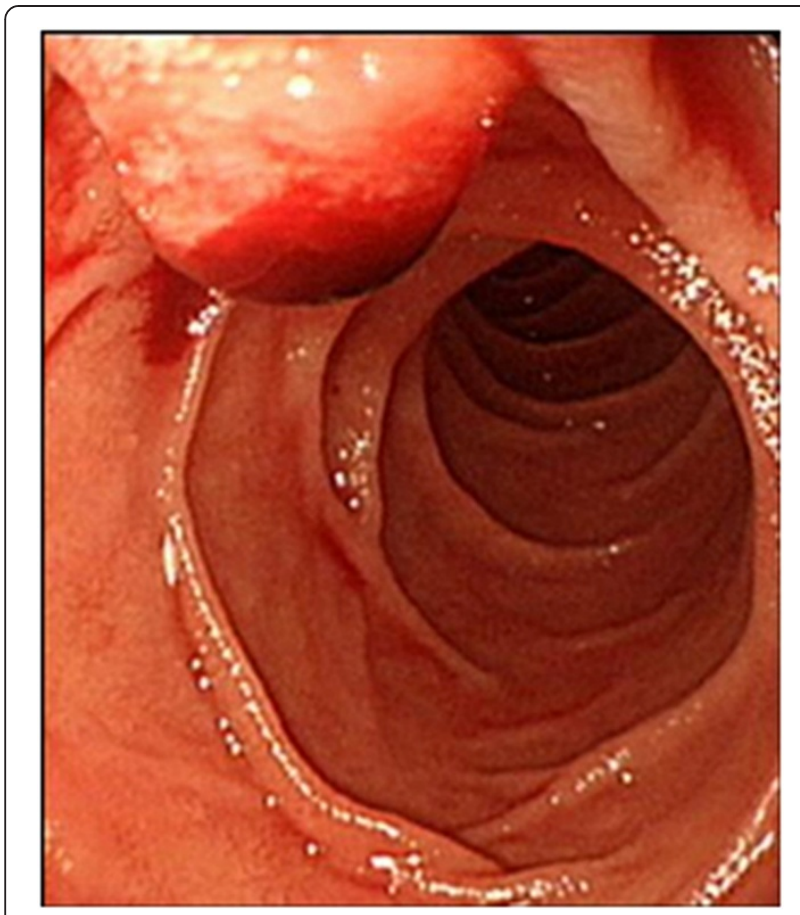

Figure 2 Upper gastrointestinal endoscopy. Fresh blood was gushing from major duodenal papilla.

the architecture and integrity of the microvasculature [11]. Therefore, inhibition of VEGF signaling can decrease the renewal capacity of the endothelial cell in response to trauma, which causes endothelial dysfunction, and eventually increases the risk of hemorrhage. Furthermore, it is considered that the weakening of the walls of major vessels by tumor erosion, necrosis, cavitation or other concurrent pathological conditions are also likely to play a central role in causing hemorrhage in patients on anti-VEGF therapy [4]. In the present case, abdominal CT performed six weeks prior to the bleeding event showed suspicious tumor invasion into the intrahepatic duct adjacent to the primary nodule; however, at that time, there was no evidence of bleeding radiologically as well as clinically. Hemobilia was found on the seventh day after sorafenib therapy began and the bleeding stopped with conservative management with sorafenib discontinuation. It was thought that the tumor had weakened the wall of the portal vein and sorafenib precipitated bleeding into the bile duct by blocking VEGF signaling.

Hui et al. [13] reported that the risk of bleeding with sunitinib, one of the VEGF receptor tyrosine kinase inhibitors, was higher in patients with nasopharyngeal carcinoma who received prior high-dose radiation therapy than those who did not. Irradiation causes damage to the endothelial cells in the capillary network and negatively influences the subsequent vascular repair process [14], and also enhances sensitivity of endothelial cells to anti-VEGF therapy [15]. In the present case, the patient received radiation therapy for two weeks prior to sorafenib administration. Previous radiation therapy may be another factor contributing to increased risk of bleeding in HCC patients on anti-VEGF therapy.

\section{Conclusions}

Sorafenib may increase the risk of bleeding in HCC patients who were primed with irradiation, by disruption of the architecture and integrity of the microvasculature, which may result from blocking of the signaling pathway of the VEGF receptor. Therefore, sorafenib should be

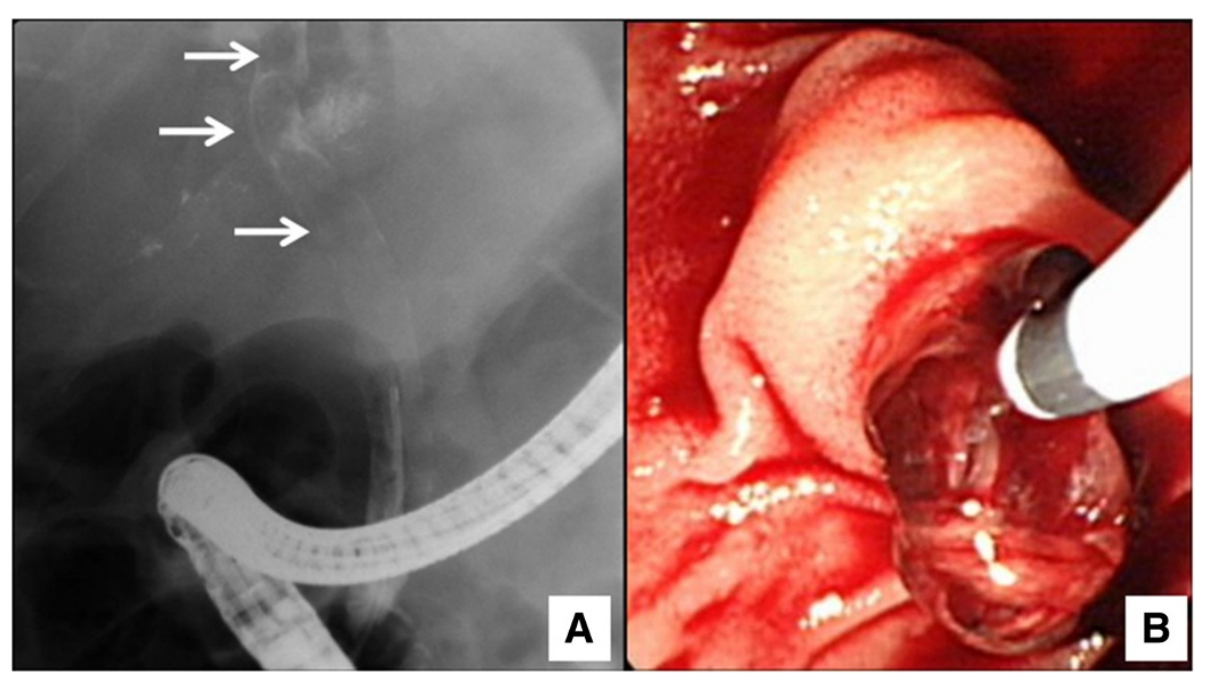

Figure 3 Endoscopic retrograde cholangiography. (A) An amorphous filling defect was seen throughout the common bile duct (arrows). (B) Blood clots were removed by balloon sweeping. 
used with caution in patients with advanced HCC, especially when combined with radiation therapy.

\section{Consent}

Written informed consent was obtained from the patient for publication of this case report and accompanying images. A copy of the written consent is available for review by the Editor-in-Chief of this journal.

\section{Abbreviations}

CT: Computed tomography; HCC: Hepatocellular carcinoma; VEGF: Vascular endothelial growth factor.

\section{Competing interests}

The authors declare that they have no competing interests.

\section{Authors' contributions}

KHY drafted the manuscript and was a member of the clinical team. MSH provided an expert endoscopic procedure and obtained endoscopic images. $\mathrm{SIH}$ oversaw clinical management and supervised the present case report. All authors read and approved the final manuscript.

\section{Authors' information}

Ha Yan Kang and Sung Hoon Moon are co-authors.

\section{Acknowledgements}

There was not any type of financial support relevant to this manuscript.

\section{Author details}

'Division of Hepatology, Department of Internal Medicine, Dankook University College of Medicine, 16-5 Anseo-dong, Cheonan 330-715, Chungnam, Republic of Korea. ${ }^{2}$ Department of Internal Medicine, Hallym University Sacred Heart Hospital, 896 Pyeongchon-dong, Anyang 431-070, Gyeonggi-do, Republic of Korea.

Received: 20 September 2013 Accepted: 16 December 2013

Published: 26 February 2014

\section{References}

1. Johns WA, Zimmerman A: Biliary obstruction due to hemobilia caused by liver cell carcinoma. Ann Surg 1961, 153:706-710.

2. Qin $L X$, Tang ZY: Hepatocellular carcinoma with obstructive jaundice: diagnosis, treatment and prognosis. World J Gastroenterol 2003, 9:385-391.

3. Kojiro M, Kawabata K, Kawano Y, Shirai F, Takemoto N, Nakashima T: Hepatocellular carcinoma presenting as intrabile duct tumor growth: a clinicopathologic study of 24 cases. Cancer 1982, 49:2144-2147.

4. Kamba T, McDonald DM: Mechanisms of adverse effects of anti-VEGF therapy for cancer. Br J Cancer 2007, 96:1788-1795.

5. Llovet JM, Ricci S, Mazzaferro V, Hilgard P, Gane E, Blanc JF, de Oliveira AC, Santoro A, Raoul JL, Forner A, Schwartz M, Porta C, Zeuzem S, Bolondi L, Greten TF, Galle PR, Seitz JF, Borbath I, Häussinger D, Giannaris T, Shan M, Moscovici M, Voliotis D, Bruix J, SHARP Investigators Study Group: Sorafenib in advanced hepatocellular carcinoma. N Engl J Med 2008, 359:378-390.

6. Abou-Alfa GK, Schwartz L, Ricci S, Amadori D, Santoro A, Figer A, De Greve J, Douillard JY, Lathia C, Schwartz B, Taylor I, Moscovici M, Saltz LB: Phase II study of sorafenib in patients with advanced hepatocellular carcinoma. J Clin Oncol 2006, 24:4293-4300.

7. Verset G, Maréchal R, Bali MA, Devière J, Van Laethem JL: Fatal hemobilia in advanced hepatocellular carcinoma invading biliary tract after treatment with sorafenib and biliary stenting. Ann Oncol 2010, 21:1381-1382.

8. Escudier B, Eisen T, Stadler WM, Szczylik C, Oudard S, Siebels M, Negrier S, Chevreau C, Solska E, Desai AA, Rolland F, Demkow T, Hutson TE, Gore M, Freeman S, Schwartz B, Shan M, Simantov R, Bukowski RM, TARGET Study Group: Sorafenib in advanced clear-cell renal-cell carcinoma. N Engl J Med 2007, 356:125-134.

9. Saif MW, Longo WL, Israel G: Correlation between rash and a positive drug response associated with bevacizumab in a patient with advanced colorectal cancer. Clin Colorectal Cancer 2008, 7:144-148.
10. El-Serag HB, Marrero JA, Rudolph L, Reddy KR: Diagnosis and treatment of hepatocellular carcinoma. Gastroenterology 2008, 134:1752-1763.

11. Vaziri SA, Kim J, Ganapathi MK, Ganapathi R: Vascular endothelial growth factor polymorphisms: role in response and toxicity of tyrosine kinase inhibitors. Curr Oncol Rep 2010, 12:102-108.

12. Je Y, Schutz FA, Choueiri TK: Risk of bleeding with vascular endothelial growth factor receptor tyrosine-kinase inhibitors sunitinib and sorafenib: a systematic review and meta-analysis of clinical trials. Lancet Oncol 2009, 10:967-974

13. Hui EP, Ma BB, King AD, Mo F, Chan SL, Kam MK, Loong HH, Ahuja AT, Zee BC, Chan AT: Hemorrhagic complications in a phase II study of sunitinib in patients of nasopharyngeal carcinoma who has previously received high-dose radiation. Ann Oncol 2011, 22:1280-1287.

14. Stewart FA, Hoving S, Russell NS: Vascular damage as an underlying mechanism of cardiac and cerebral toxicity in irradiated cancer patients. Radiat Res 2010, 174:865-869.

15. Zips D, Eicheler W, Geyer P, Hessel F, Dörfler A, Thames HD, Haberey M, Baumann M: Enhanced susceptibility of irradiated tumor vessels to vascular endothelial growth factor receptor tyrosine kinase inhibition. Cancer Res 2005, 65:5374-5379.

doi:10.1186/1752-1947-8-72

Cite this article as: Kang et al:: A unique bleeding-related complication of sorafenib, a tyrosine kinase inhibitor, in advanced hepatocellular carcinoma: a case report. Journal of Medical Case Reports 2014 8:72.

\section{Submit your next manuscript to BioMed Central and take full advantage of:}

- Convenient online submission

- Thorough peer review

- No space constraints or color figure charges

- Immediate publication on acceptance

- Inclusion in PubMed, CAS, Scopus and Google Scholar

- Research which is freely available for redistribution 